\title{
IMÁGENES EN EL ABISMO. ANTÍN, CORTÁZAR E INTIMIDAD DE LOS PARQUES ${ }^{1}$
}

\author{
Marcos Zangrandi \\ Instituto de Literatura Hispanoamericana Facultad de Filosofía y Letras, Universidad de \\ Buenos Aires. Consejo Nacional de Investigaciones Científicas y Técnicas (CONICET). \\ marcoszangrandi@gmail.com
}

Recostado sobre la cama, Héctor Morand (interpretado por el actor español Francisco Rabal) lee en voz alta el relato "Continuidad de los parques" de Julio Cortázar. A su lado y de espaldas, Teresa (Dora Baret) lo escucha turbada y temerosa. El libro que el personaje tiene en sus manos es fácilmente reconocible: es un ejemplar de Final del juego que editorial Sudamericana editó en 1964. Entre la voz de Morand se insertan imágenes en montaje alternado: una cámara subjetiva que atraviesa rápidamente una arboleda; pasos precipitados que suben precipitadamente las escaleras hacia una casa. Tal como sucede en el texto de Cortázar, la lectura parece invocar la convergencia de planos y metaplanos ficcionales: a espaldas de la lectura de Morand se erige el engaño, la traición y la muerte.

Estas imágenes pertenecen a la película Intimidad de los parques, filmada por Manuel Antín a fines de 1964. El guión, escrito por Antín, Raimundo Calcagno y Héctor Grossi, integraba en un solo argumento dos narraciones de corte fantástico. Se planteaba, efectivamente, como una adaptación de los relatos "El ídolo de las Cícladas" y "Continuidad de los parques" (ambos incluidos en la colección Final del juego). Era, asimismo, la tercera transposición que este cineasta realizaba de los textos de Julio Cortázar, luego de La cifra impar (1961, sobre "Cartas de mamá") y de Circe (1963, sobre el cuento homónimo), que fue coescrita con el narrador.

La singularidad del lector de Intimidad de los parques es su potencia paradójica. Se trata de un personaje de un relato (Morand, de "El ídolo de las Cícladas") que lee una ficción ("Continuidad de los parques") del mismo libro en el cual surgen ambas narraciones. Lee, además, un relato que tal vez él esté protagonizando -las tramas se

1 Este artículo está inscripto en el proyecto colectivo "Lectura, lectores y escritores en Argentina” (UBACyT C012 2012-2015) financiado por la Secretaría de Ciencia y Técnica de la Universidad de Buenos Aires. 
confunden; el argumento de un peligroso triángulo amoroso se apodera de una y otra narración- $-^{2}$. No solo eso: el personaje tiene en sus manos un libro del cual proceden él y el resto del montaje ficcional. Y acaso el espectador, frente a la película de Antín (o de escuchar el relato en la voz del actor), plácido sobre su butaca, no esté sino a poco de ser asesinado por el amante de su pareja. Lectores que leen relatos sobre lectores; lectores observando a lectores en una compleja puesta en abismo.

¿Cuál es la razón por la que Manuel Antín decide poner en escena-hacer visible- esta imbricada construcción alrededor de la imagen de un lector de un relato de Cortázar? ¿Por qué, en este mismo sentido, situar el cine argentino no en la simple adaptación de un texto literario a la pantalla grande (del cual hasta entonces había numerosísimos casos), sino acercarlo a través de estas operaciones al campo de una cultura intelectualizada, moderna y sofisticada?

Desde muy joven, Manuel Antín tenía una vocación clara: quería convertirse en escritor. De hecho, antes de comenzar a filmar ya había publicado tres poemarios con fondos propios. Según su recuerdo, "mi vocación era la literatura y el teatro, ya había estrenado dos obras de teatro. Mi fantasía era ser autor teatral, novelista, cuentista o poeta..." (Peña 31). Lector voraz, en 1956 encontró en la biblioteca de un amigo un ejemplar de Bestiario de Julio Cortázar, por entonces un escritor todavía poco conocido fuera del circuito literario argentino (v. Canoso; Peña). La lectura del libro significó un vuelco en la carrera de Antín. En esos cuentos, con sus desestructuraciones temporales y sus juegos narrativos, encontró aquello que él hubiera querido escribir: "Era como si al mundo que yo tenía, él le hubiera puesto letra. Y me encontraba con sus historias que me parecían las mías (...). Descubrí que era el escritor que yo no era; 'mi otro yo escritor"' (Canoso 14). Por sobre estos descubrimientos, en Cortázar descubrió la semilla de su trabajo cinematográfico. Pocos años después, una noche, en un café, les relató a unos amigos "Cartas de mamá" (incluido en Las armas secretas, editado en 1959) como si fuera no un cuento sino una película que había visto recientemente. Al final de su narración, Antín reveló la verdad. Había sido tan elocuente que, de inmediato, los dos amigos, Axel Harding y Raúl Schön, le propusieron convertir ese relato en una película, ofreciéndose ellos mismos como productores (v. Canoso). Este fue el inicio de la carrera como director de Manuel Antín. Puede observarse, a partir de esta anécdota, que su iniciativa se construye bajo el modo de un relato literario y de una vocación marcadamente intelectual, lejos del formato industrial del cine. Luego, que la narrativa que lo fascina posee rasgos novedosos, y en este sentido, se siente atraído por llevar a la pantalla grande un plano modernizador. Finalmente, que Antín poseía una interesante habilidad de hacer pasar por cine un texto literario.

Tan pronunciada era esta impronta intelectual para la nueva camada de cineastas a la que Antín pertenece, que no les preocupaba tener conocimientos técnicos para filmar.

$2 \quad$ La imagen del lector en Intimidad de los parques, con todas sus diferencias, recuerda puntualmente el triángulo amoroso alrededor de la lectura de Las afinidades electivas en Jules y Jim, la célebre película de François Truffaut de 1962. 
Según el propio Antín, "en esa época nosotros filmábamos con equipos del sindicato (SICA). Los únicos que no sabían de cine eran los directores. Los demás eran los que fabricaban la película. Iluminadores, cameraman, yo no sé ni cargar una cámara" (Antín, comunicación personal [29 de setiembre de 2014]). Ello da cuenta de la necesidad de los realizadores argentinos de los años 1960 de adquirir los recursos de una cultura letrada. No se cargaban cámaras ni reflectores, pero sí era imperioso para un cineasta, en cambio, poseer inquietudes intelectuales: leer, ser cinéfilo, escribir -escribir a través del cine-. Hay en ello una seña de exclusivismo, indudablemente, aunque ello no representaba el desprecio directo por los grandes públicos, sino la de prestigiar el cine y la propuesta de llevar una expresión estética masiva hacia otro nivel, divergente de los modos clásicos (cf. Russo).

Para comprender este gesto es necesario considerar el proceso de transformaciones a la que estuvo condicionado el cine argentino desde los años 1950: dificultades económicas de los grandes estudios, desguace del sistema de apoyo estatal a partir de 1955, nueva ley de cine dictada en 1957, crisis de los regímenes de representación y narración cinematográfica, entre los más importantes (v. Peña; Kriger; España). La profunda crisis propicia que algunos cineastas (Feldman, Alventosa, Torre Nilsson, Kuhn, Kohon, Murúa, Favio y otros) comenzaran a realizar un cine con una perspectiva y unos alcances distintos de los que habían tenido hasta entonces. En todos ellos (que en su mayoría trabajan de forma independiente) se destaca la clara intención de modernización del lenguaje cinematográfico y la búsqueda de un estatus cultural prestigiante, similar al que tenía la literatura en esa misma época. A la vez, para muchos escritores el cine se torna un territorio sumamente atractivo. Es por ello que las colaboraciones y adaptaciones (algunas más sostenidas que otras) entre escritores de prestigio y cineastas se encuentran en esta época: Bioy Casares (El crimen de Oribe, 1950), Borges (Días de odio, 1953; Hombre de la esquina rosada, 1962), Bianco (Las ratas, 1963), Sábato (El túnel, 1952), Denevi (Rosaura a las diez, 1958), Manauta (Las tierras blancas, 1959), Kordón (Alias Gardelito, 1961), y otros (Bottone 1964; Couselo 1981).

Sería difícil entender este proceso por fuera de las transformaciones que se producían en el mundo. Efectivamente, la década de 1960 es la época dorada de la modernidad cinematográfica; la instancia en que los modos narrativos, formales, representacionales y de recepción que habían funcionado desde los años 1920, se ponen en cuestión (cf. Russo; Bordwell et al.; Sánchez Noriega). Esta modernidad se dispara en distintos aspectos: reflexión sobre el lenguaje de expresión, quiebre de la mímesis clásica-esto es, fidelidad a lo probable-, revisión de los géneros, disyunciones espaciales y temporales, complejidad narrativa, ambigüedad causal, presencia del realismo, entre otras. Entre estos rasgos se destaca la impronta autoral hacia un cine que se configura como una materia plástica. Los críticos y realizadores de la influyente crítica francesa (principalmente en las figuras de Astruc, Bazin y Truffaut) se reiteran sobre la idea del cine como escritura, en la presencia del director como un autor y en las posibilidades expresivas de la pantalla grande. El cineasta parecía, bajo esta perspectiva, ingresar a una actividad y a una cultura letradas.

En este marco, resulta no solo plausible sino necesaria la perspectiva de un cine de vocación intelectual como el que se propone Antín y sus transposiciones de las narraciones de Cortázar, un escritor, además, que se abría como puntal de la modernidad literaria 
latinoamericana -en 1963 había publicado Rayuela-. Se trataba, entonces, menos de un gesto de elitismo que de la señal de un cine que convergía, bajo sus propios modos, con transformaciones cinematográficas mundiales. También en la misma perspectiva de confluencia se destaca el interés del narrador por las posibilidades que le puede otorgar el cine a su literatura. Antín recuerda el vínculo de complementariedad entre ambos:

En alguna oportunidad él me preguntó por qué yo filmaba sus cuentos. Y le dije "Porque vos tenés lo que yo quisiera tener para escribir", a lo que él me respondió "Ahora me das una linda idea, ya que yo quisiera hacer lo que vos hacés". Yo amaba la literatura y me hubiera gustado escribir como él; él adoraba el cine y le hubiera gustado ser director. Se dio entre nosotros una de esas historias borgeanas -o por qué no cortazarianas - de caminos cruzados, causalidades y dobles (Sández 34).

Más que en sus adaptaciones anteriores, Intimidad de los parques implicaba una fuerte apuesta de Antín por reforzar un cine apegado a la esfera de la literatura. Poner en escena la figura abismal de Morand leyendo "Continuidad de los parques" era, en este sentido, una forma de apuntalar la modernidad sobre la que quería erigirse. Modernidad que tenía señales claras en el film: distancia reflexiva, autorreferencialidad, presencia del mundo intelectual, la complejidad espacial y temporal, entre otros aspectos.

A ellos se suman, por un lado, la repetición artificiosa y contigua de una misma acción, un estilema sin ninguna funcionalidad narrativa o descriptiva que subraya el planteo estético-formal del film. Por el otro, la presencia, por momentos, de un realismo que rompe la verosimilitud clásica. Hay una escena que es ejemplar de esto: Teresa (Dora Baret), vestida y peinada a la moda europea, camina perdida entre la multitud que sigue al Señor de los Milagros en el centro de Lima. El montaje alterno muestra los primeros planos de la actriz en medio del gentío y tomas cenitales de los miles de fieles junto a la imagen religiosa. Ella actúa; los cientos de personas que la rodeaban, no. Algunos miran extrañados a la cámara; otros observan, intrigados, a Dora Baret y al cameraman que la sigue. La incomodidad pone de manifiesto la tensión tradición- modernidad en el que está inscripta la imagen. La introducción de este tipo de registro mimético, ausente en las películas anteriores de Antín, hacía presente la novedosa imagen de la posguerra -cuya referencia inmediata era el cine italiano de los años 1940 y 1950-; la imagen del realismo cinematográfico que busca la utopía de la imagen total (v. Stam), a la vez que afirma el poder de la cámara por encima de cualquier condicionamiento coyuntural.

Puede advertirse, por otro lado, que en el film de Manuel Antín los aspectos fantásticos de los cuentos de Cortázar están subordinados a una línea argumental psicológica, tal como ya había sucedido en sus adaptaciones anteriores, La cifra impar y Circe. Lo extraordinario en "El ídolo de la Cícladas" (una estatua ancestral que provoca extraños y violentos deseos en los personajes) aparece como telón de fondo en la película. El itinerario central de la narración está inclinado hacia el triángulo pasional entre Teresa, Héctor y Mario. Y este es el punto de confluencia con el otro relato traspuesto ("Continuidad de los parques"). Según se desprende del film, Antín no parecía querer indagar en los rasgos mágicos de los cuentos de Cortázar. En cambio, la dimensión fantástica en Intimidad de los parques está presente en el empleo de una temporalidad por fuera de la cronología. Raccontos, flashes, relatos dentro de relatos, fusión de planos. La propuesta, sobre todo en 
los tramos finales del film, es un tiempo que pierde un orden (lineal, circular o alterno) y se despliega en una especie de exterior temporal sin perder el argumento. David Oubiña advierte con acierto este aspecto en el film:

Hasta aquí, Antín había trabajado sobre dos series paralelas que se comunicaban en un vaivén de pasajes. Ahora, la dimensión de futuro no viene a agregar una tercera serie sino que tiende a fusionarlas, diluyendo el centro. (...) Si bien el relato se enuncia desde el presente, permanentemente quiebra la dirección hacia delante para fluir en todas direcciones y construir una serie múltiple, hecha de fragmentos de distinta temporalidad: una "narración acrónica", en donde el tiempo no resulta una especificidad diferencial (Oubiña 25-26)

En los relatos de Cortázar hay tres líneas constitutivas: magia ancestral, alteración cronológica y triángulo amoroso. Antín toma y enfatiza los dos últimos como modo de afirmar un cine innovador y moderno. Para ser justos, hay que señalar que en el guión del film, el primer aspecto (el fantástico) tiene mayor espacio y presencia. Una faceta que fue relegada en la realización del film.

Ese modo en que el guión introducía los elementos mágicos fue, justamente, el punto de discusión central entre Antín y Cortázar en el momento en el que se confeccionaba el libro cinematográfico. El cuento "El ídolo de las Cícladas" se centra en un descubrimiento de una estatuilla ancestral que despierta sobrenaturalmente extraños deseos en los personajes. En el relato, Somoza se transforma, por efecto de fuerzas extrañas, en una especie de sacerdote de una deidad antigua (Haghesa) que lo empuja a atacar a Morand con el fin de ofrecer un sacrificio. En Intimidad de los parques, en cambio, la estatuilla, que pertenece a una cultura precolombina, tiene un poder limitado en relación con los celos y con las psicologías de Héctor, Teresa y Mario. La propuesta del guión estaba lejos de satisfacer a Cortázar, que señalaba las diferencias en el concepto de magia entre ambos:

La noción de magia es distinta en vos y en mí, no cabe duda, pero el hecho de que notes esa carencia prueba -creo- que has sido sensible al enorme desajuste que hay entre las razones del drama y su espectacular desenlace a hachazo limpio (...) Te has negado a admitir el lado demoníaco del cuento. Y sin eso, creeme, no hay cuento. Más todavía: si querés hacer una película esencialmente psicológica-que es tu fuerte, es evidente- deberías buscar las ideas por otro lado. Un cuento de Moravia, digamos, te daría muchos más elementos que un cuento mío. O uno de Goytisolo, o de Salinger: cualquiera de los que no salen de la realidad diurna, y ahondan en ella admirablemente. Mis cuentos (...) presuponen inalienablemente una aceptación de fuerzas ocultas (Cortázar, Cartas 537).

Se debe considerar, para complementar esta observación, la distancia que Cortázar marcaba en esta misma carta de julio de 1964 respecto de lo que él señalaba desdeñosamente como "los novelistas del cine" (Cartas 538), Antonioni y Fellini, y, en cambio, el aprecio hacia los filmes de corte surrealista o absurdo que destaca en otros momentos (Cocteau, Buñuel, los hermanos Marx). Estaba poniendo en claro, de este modo, el tipo discursivo que prefería para sus relatos. 
El desacuerdo entre el director y el narrador también se extendía a las locaciones elegidas y a las modificaciones que se tuvieron que hacer en consecuencia. Manuel Antín había obtenido financiamiento de un productor peruano, por lo cual optó por cambiar las islas del Egeo por las ruinas de Machu Picchu. En otras palabras, debía transformar el mármol en piedra, convertir una antigua cultura mediterránea en una incaica. Este aspecto contrariaba a Cortázar, quien le apuntaba que los pueblos andinos no se habían hecho conocidos por sus sacrificios sangrientos, por lo que se le restaba verosimilitud al relato.

Por otra parte, y según se desprende de las cartas que se enviaron en la época, las ideas de Antín para la película parecían ser demasiado rebuscadas u oscuras para Cortázar, aspecto que va desde el título (Intimidad de los parques o el alternativo La infiel) hasta la inclusión del cuento "Continuidad de los parques" en el guión. La idea del relato dentro del relato era tan explícita y la referencia era tan directa que desagradaba a Cortázar, como se lo expresó a Antín:

Qué querés, no he terminado de entender la intercalación de "Continuidad de los parques" en la forma que vos lo intercalás. (...) La mención de mi nombre en el diálogo la RECHAZO DE PLANO. (...) esa lectura de algunos pasajes de "Continuidad....", así sueltos no tienen el menor sentido (546).

Aunque una segunda versión del guión obtuvo la venia de Cortázar, éste nunca expresó su completa anuencia con Intimidad de los parques. Pensaba, según se entiende de los intercambios entre el narrador y el cineasta, que la película se arriesgaba sobre elementos demasiado difíciles de resolver estética y técnicamente. Como le señaló en una misiva del 19 de agosto de 1964:

Sigo creyendo que es tu obra más comprometida, más peligrosamente resbaladiza. Un error, y nos vamos al agua. La cosa es demasiado extrema, toca terrenos demasiado hondos como para tolerar un margen de aciertos relativos. Clavás la flecha en el medio del blando o perdés todo (555).

Tantas apuestas de Antín eran ciertamente osadas y esos riesgos malograron el resultado. Filmó en Perú durante dos semanas sin poder ver lo que se realizaba día a día por problemas técnicos. Cuando retornó a Buenos Aires para revelar el film, descubrió que el 40 por ciento del celuloide tenía estática por efecto de la altura y de la alta temperatura de la sierra peruana. Tuvo que montar la película con el material restante. El resultado dejó inconforme al director y al mismo Julio Cortázar. El film pasó rápidamente por las salas de Buenos Aires y con escándalo por las de Lima. Es que los promotores peruanos la publicitaron como una cinta erótica. En una de las proyecciones, los espectadores, decepcionadas sus expectativas, protestaron, provocaron disturbios e incendiaron las butacas. "Se cumplió la profecía de Cortázar" - señala aún resignado Antín- "cuando advirtió que un mínimo inconveniente podía echar a perder una película excelente” (Sández 78).

Independientemente de este derrotero adverso, la imagen de la lectura en Intimidad de los parques, como si se tratara de una escritura que ha sobrevivido a un texto erosionado, proyecta el trazado de un cine sofisticado y moderno, señala una convergencia sinérgica 
entre escritores y cineastas y, finalmente, estipula una exigente formulación del espectador incluyéndolo dentro de la puesta en escena como un lector.

\section{BIBLIOGRAFÍA}

Antín, Manuel; Raymundo Calcagno y Héctor Grossi. Intimidad de los parques [guión cinematográfico]. Buenos Aires: s/e, 1964.

Bordwell, David; Janet Staiger y Kristin Thompson. El cine clásico de Hollywood. Barcelona: Paidós, 1996.

Bottone, Mireya. La literatura argentina y el cine. Santa Fe: Universidad Nacional del Litoral, 1964.

Canoso, María Lyda. Cartas de cine. Julio Cortázar a Manuel Antín (1961-1975). Buenos Aires: Universidad del Cine, 1995.

Cortázar, Julio. Las armas secretas. Buenos Aires: Sudamericana, 1959.

Cartas 1955-1964. Buenos Aires: Alfaguara, 2012.

Couselo, Jorge. "Literatura argentina y cine nacional". Capítulo. La historia de la literatura argentina, 96. Buenos Aires: CEAL, 1981. 601- 624.

España, Claudio. "Emergencia y tensiones en el cine argentino de los años cincuenta". Nuevo Texto Crítico 19- 20 (1997): 45- 73.

comp. Cine argentino. Modernidad y vanguardias 1957-1983. Buenos Aires: Fondo Nacional de las Artes, 2005.

Kriger, Clara. Cine y peronismo. El estado en escena. Buenos Aires: Siglo XXI, 2009.

Oubiña, David. Manuel Antín. Buenos Aires: CEAL, 1994.

Peña, Fernando M., comp. Generaciones 60/90. Cine argentino independiente. Buenos Aires: MALBA, 2003.

Cien años de cine argentino. Buenos Aires: Biblos, 2012.

Russo, Eduardo. El cine clásico. Itinerarios, variaciones y replanteos de una idea. Buenos Aires: Manantial, 2008.

Sández, Mariana. El cine de Manuel. Un recorrido sobre la obra de Manuel Antín. Buenos Aires: Capital Intelectual, 2010.

Sánchez Noriega, José Luis. De la literatura al cine. Teoría y análisis de la adaptación. Barcelona: Paidós, 2000.

Stam, Robert. Teorías del cine. Una introducción. Barcelona: Paidós, 2001. 